\title{
Inulin-type fructans and bone health: state of the art and perspectives in the management of osteoporosis
}

\author{
Véronique Coxam \\ Groupe Ostéoporose, U3M, INRA Theix, 63122 Saint-Genès Champanelle, France
}

\begin{abstract}
If the primary role of diet is to provide sufficient nutrients to meet the metabolic requirements of an individual, there is an emerging rationale to support the hypothesis that, by modulating specific target functions in the body, it can help achieve optimal health. Regarding osteoporosis prevention, since Ca is most likely to be inadequate in terms of dietary intake, every strategy targeting an improvement in Ca absorption is very interesting. Actually, this process may be susceptible to manipulation by fermentable substrates. In this light, inulin-type fructans are very interesting, even if we need to gather more data targeting bone metabolism before health professionals can actively advocate their consumption to prevent senile osteoporosis. Besides targeting the prevention of postmenopausal osteoporosis, inulin-type fructans still remain a source for putative innovative dietary health intervention. Indeed, given in combination with isoflavones, they may have a potential for maintaining or improving the bone mass of human subjects, by modulating the bioavailability of phyto-oestrogens.
\end{abstract}

Inulin: Oligofructose: Osteoporosis: Prevention

With the human race experiencing a progressive increase in life expectancy, all industrialised countries face a continuous increase in the number of the elderly and, consequently, a growing prevalence of chronic diseases. Since women experience a longer life expectancy, they are more likely to require increased medical care leading to high overall acute and chronic health care cost. This is why osteoporosis, a generalised condition of the bone whose hallmark is increased bone fragility, has become a major health and socio-economic problem worldwide.

It has become commonplace to refer to osteoporosis as multifactorial and two main divisions were suggested many years ago: postmenopausal and senile osteoporosis. Actually, there is an overwhelming body of evidence emphasising that gonadal failure at the time of menopause causes osteopenia and that the administration of oestrogens in postmenopausal women prevents this loss, while in the elderly, because bone is mainly built up with $\mathrm{Ca}$ for which deficiency is common, the primary goal of a nutritional strategy is to provide a sufficient bioavailable amount of this nutrient to optimise the genetic potential (Coxam \& Horcajada, 2004).

Basically, research in nutrition has led to an exciting emerging rationale supporting the hypothesis that, by modulating specific target functions in the body, diet can help achieve optimal health. Furthermore, it is commonly believed that nutrients interact, thereby altering one another's requirements. In fact, what may not have been expected is the considerable magnitude of these interactions with regard to critical bone nutrients. The effect of non-digestible carbohydrates on nutrients involved in bone health is a good example of such modulations and, in this light, they may provide a useful tool to prevent bone loss in both postmenopausal and ageing women.

\section{The problem of osteoporosis}

Osteoporosis has been defined as a systemic disease characterised by low bone mass and microarchitectural impairment of bone tissue, with a consequent increase in bone fragility and susceptibility to fracture (Consensus Development Conference, 1993).

The current lifetime risk of osteoporotic fracture for 50-yearold women is estimated at nearly $40 \%$, higher than the total risk of having breast, endometrial and ovarian cancer (Cummings et al. 1985). This is why this health problem is reaching near-epidemic proportions worldwide. Indeed, the disease affects around 75 million people in Europe, the United States and Japan combined, including one in three postmenopausal women, the majority of elderly people and a substantial number of men (Consensus Development Statement, 1997). On a global scale, an average of 407000 hip, 270000 clinically diagnosed vertebral and 340000 forearm fractures are recorded each year in Europe (Cooper et al. 1992). Furthermore, if the current trends continue, confident projections in the next two decades support the hypothesis that the magnitude of this disorder will worsen by $60 \%$, unless a suitable intervention can be devised, leading to about 650000 hip fractures in Europe (Cooper et al. 1992). Although the disorder is only clinically relevant once a fracture has occurred, it results in a considerable fiscal drain in terms of health care, the corresponding hospital expenditure being higher than that for other pathologies of the elderly, i.e. more than $€ 10$ million (Report from the European Community, 1999). Moreover, approximately $50 \%$ of elderly hip-fracture patients do not regain full independence and more than $20 \%$ die within 6 months, through 
complications connected with the fracture. Thus efforts are needed to improve prevention measures and integrate complementary alternative therapies of proven value.

As currently available treatments never restore the microarchitecture of the bone, and because bone mineral status in later life is the net outcome of lifelong influences on skeletal mineral accretion and loss, there is now an emerging rationale for early intervention, which may actually be best achieved by initiating sound health behaviours early in life and continuing them throughout life.

Prevention through dietary means is especially challenging in technologically advanced societies. For this purpose, a large number of nutrients have been considered as possible determinants of bone health. However, because among the bone-building nutrients $\mathrm{Ca}$ is the most likely to be inadequate in terms of dietary intake (Weaver, 2000), functional foods designed to prevent osteoporosis could work by providing $\mathrm{Ca}$, a key nutrient for bone development and maintenance, or by enhancing its absorption or retention to build peak bone mass or to suppress bone turnover (Weaver \& Liebman, 2002).

\section{The rationale for calcium}

$\mathrm{Ca}$ is critical to achieve optimal peak bone mass and modulate the rate of bone loss associated with ageing. Therefore, if it is inadequate during growth, the full genetic programme for skeletal mass cannot be achieved then if Ca intake is too low to offset obligatory losses, acquired skeletal mass cannot be maintained (Heaney, 2003).

The adult body contains about $1 \mathrm{~kg} \mathrm{Ca}$ and all but $1-2 \%$ (as a messenger in a variety of neurological and other cellular signalling events) is in bone. As a result, bone mineralisation is coupled to $\mathrm{Ca}$ intake and absorption and any factor that affects the amount retained by the body will alter total bone mineral mass. Furthermore, given the small metabolic pool of $\mathrm{Ca}$, circulating concentration is mainly maintained at the expense of the skeletal compartment, i.e. from an increased bone resorption (Cashman, 2002). Consequently, the size of the bony reserve for $\mathrm{Ca}$ will depend on the daily balance between absorbed intake and excretory loss.

\section{Calcium and bone health (Fig. 1)}

During childhood. The demand for Ca during this critical period of skeletal growth is probably greater than at any other time of the life cycle. Results from clinical trials are relatively consistent and the emerging picture is that any increase in Ca intake may result in higher bone mineral acquisition rates in children and adolescents, and the improvement is more pronounced when baseline $\mathrm{Ca}$ intake is low.

Indeed, Lee et al. (1993), recording the Ca intake from birth up to 5 years, found a positive correlation with bone mineral density (BMD) at the wrist. In a 3-year supplementation study (718 mg $\mathrm{Ca}$, baseline being at $894 \mathrm{mg}$ ) carried out in twins, an increased BMD was reported at the spine and radius (Johnston et al. 1992). Similar data were observed in adolescent girls given either extra dairy products (Chan et al. 1995); or $500 \mathrm{mg}$ supplemental Ca for 18 months (in addition to dietary levels of $960 \mathrm{mg} / \mathrm{d}$ ), a $4 \%$ gain in total skeletal Ca being demonstrated (Lloyd et al. 1993). These results are consistent with the bone retention of approximately $1-5 \%$ (depending on the skeletal site) associated with an increased Ca intake in the following trials: Andon et al. (1994), Lee et al. (1994). However, this relationship is much less robust during pubertal growth spurt than during prepuberty, the growth pattern being mainly dominated by sex hormones (Anderson et al. 1996). Furthermore, even if the skeletal benefits are not maintained when the Ca supplementation is withdrawn (Slemenda et al. 1993; probably because of the 'bone remodelling transient' phenomenon), the gain in bone density throughout the first several decades translates to lower risk of fracture later in life (Matkovic et al. 1979, 1990). It is thus likely that variations in Ca nutrition early in life can account for as much as a $5-10 \%$ difference in peak bone mass and contribute more than $50 \%$ to the hip-fracture rates later in life. Indeed, there is evidence that a high past intake of milk is beneficial to bone health later in life (Reid \& New, 1997).

In adults/premenopausal women. BMD is relatively stable between the ages of twenty and fifty; this is probably why trials examining the effect of $\mathrm{Ca}$ in premenopausal women have shown conflicting results. For example, a 4-year study of $500 \mathrm{mg}$ supplementation had no significant effect on BMD (Smith et al. 1989), while a 3 -year study, increasing the Ca intake by $610 \mathrm{mg} / \mathrm{d}$, resulted in less bone loss than in the placebo group (Baran et al. 1990). In the same way, total body BMD was increased after 1 year of supplementation with $1000 \mathrm{mg} / \mathrm{d}$ in the trial published by Rico et al. (1994).

To summarise, a meta-analysis performed on thirty-three eligible trials in young adults found that $1000 \mathrm{mg} \mathrm{Ca} / \mathrm{d}$ could prevent the loss of $1 \%$ bone per year at all sites except the ulna (Welten et al. 1995).

In early postmenopausal women. Menopausal status is the overriding factor determining bone loss in women in their early fifties. Thus, given the tremendous impact of gonadal hormones on bone health, a high $\mathrm{Ca}$ intake will not offset osteopenia that occurs immediately following menopause.

Indeed, according to supplemental studies, an increase in Ca consumption during early menopause is not effective in retarding bone loss from trabecular regions of the skeleton, although it appeared to slow cortical bone loss (Polley et al. 1987; Riis et al. 1987; Smith et al. 1989; Dawson-Hughes et al. 1990; Aloia et al. 1994; Elders et al. 1994; MacDonald et al. 2004). However, these changes are very small and tend not to be sustained.

Nevertheless, if the effect of $\mathrm{Ca}$ is small, it is still important because it is quite clear that the bone loss observed in untreated postmenopausal women is exacerbated by a $\mathrm{Ca}$ deficiency. Thus, in a Yugoslavian population, the bone mass was found to be $5-6 \%$ greater in the district with high $\mathrm{Ca}$, compared to the area with low intake (Matkovic et al. 1979).

In the elderly. The rationale for recommending a high $\mathrm{Ca}$ intake in the elderly lies in the decrease in Ca absorption efficiency with age. Several studies have shown Ca supplementation to be effective in reducing bone loss at various sites, especially the hip (Dawson-Hughes et al. 1990; Nelson et al. 1991; Reid et al. 1993; Chevalley et al. 1994; Devine et al. 1995; Prince et al. 1995; Reid et al. 1995).

To summarise, in the meta-analysis published by Heaney (1996), twenty-three out of twenty-eight Ca intervention studies that excluded early postmenopausal women were positive, and this is verified in all the twelve that controlled for $\mathrm{Ca}$ intake. Another meta-analysis yielded similar results, i.e. a Ca supplementation of $1000 \mathrm{mg} / \mathrm{d}$ could prevent loss of approximately $1 \%$ of the bone mass per year in postmenopausal women not on oestrogen (Cumming, 1990). 


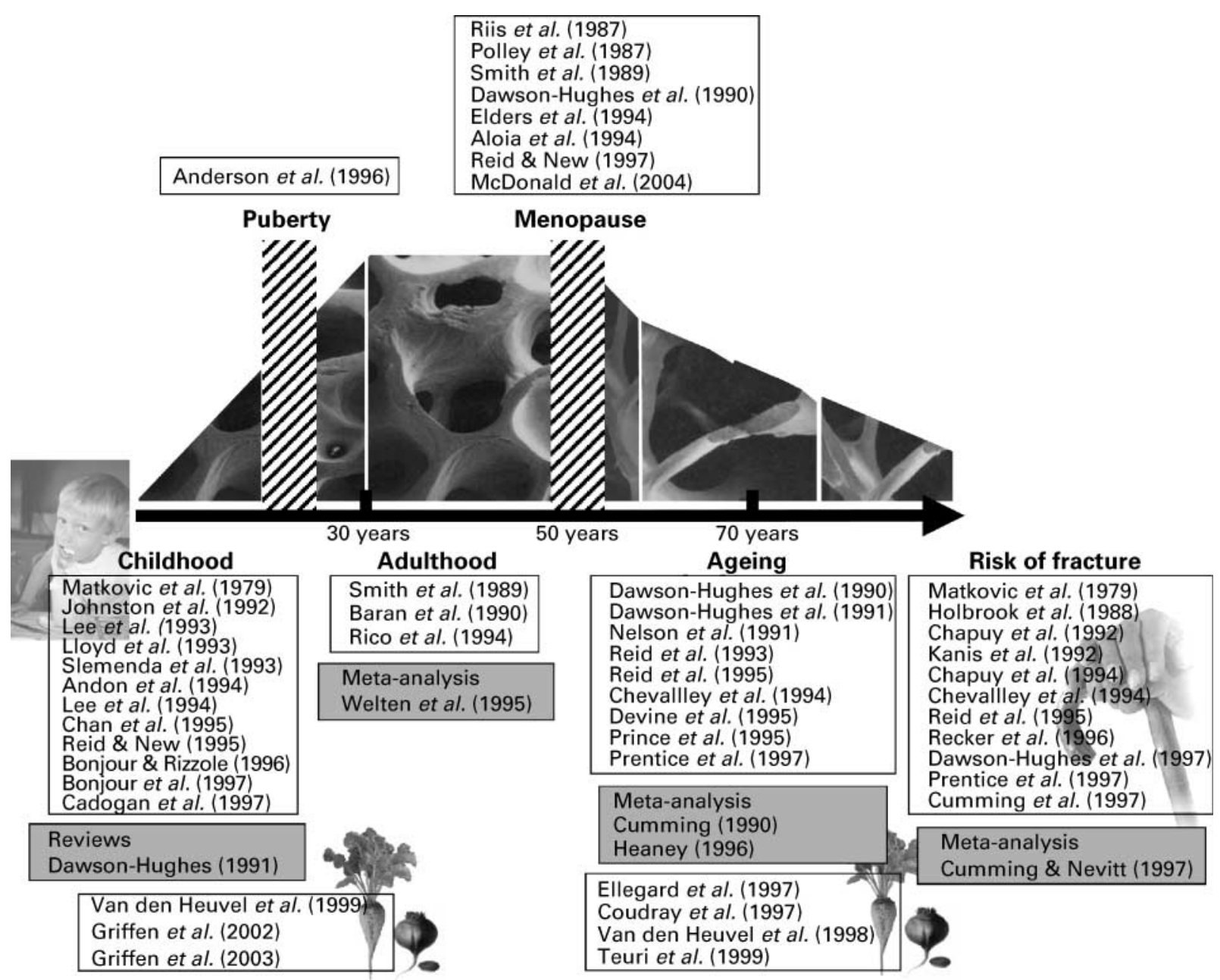

Fig. 1. (A) Main clinical trials ( $\square$ ) and reviews or meta-analyses ( $\square$ ) reporting the effect of Ca supplementation on bone health. (B) Supplementation studies with inulin-type fructans (

Risk of fracture. Although the increase in BMD from additional $\mathrm{Ca}$ intake is encouraging, the most important outcome variables are bone fractures, and the body of evidence suggests that $\mathrm{Ca}$ supplementation may be effective in preventing them.

These data are supported by the retrospective study by Matkovic et al. (1979). Moreover, Reid et al. (1995) found, after 4 years of supplementation, nine fractures in seven women in the placebo group and only two in the Ca group. In the same way, in the study by Chevalley et al. (1994) six of the fiftyfour subjects on $\mathrm{Ca}$ developed a vertebral fracture, a much lower figure than that observed in the placebo group. Impressive reductions in hip fractures have also been achieved in elderly women, living in nursing homes, who take a combination of Ca and vitamin D (Chapuy et al. 1992, 1994), with protection becoming apparent after 6-12 months of treatment and by 18 months fractures being reduced by more than $30 \%$. Again, individuals on high $\mathrm{Ca}$ intake were found to have fewer fractures in the 14-year longitudinal study by Holbrook et al. (1988). Finally, a significant reduction in the relative risk of fracture was also demonstrated in the large case-control study by Kanis et al. (1992).

In conclusion, most studies are consistent and support the public health policy regarding $\mathrm{Ca}$ intake. This was confirmed by the meta-analysis of sixteen observational studies that reported a small but consistent reduction of fractures $(1 \mathrm{~g} / \mathrm{d}$ being associated with a $24 \%$ reduction in the risk of hip fracture; Cumming \& Nevitt, 1997).

\section{Calcium dietary intakes}

Because, in an adult, the bone mass present at any time in life is a function of the amount achieved at maturity and lost with ageing, and given the fact that the body cannot store $\mathrm{Ca}$ in bone above the level of current need, the $\mathrm{Ca}$ requirement remains high throughout life. This is reflected by a long history of $\mathrm{Ca}$ intake recommendations, even if controversy continues concerning the levels to be recommended (Mertz, 2000).

Current exposure in contemporary people is often only a small fraction of what their primitive ancestors experienced (Heaney, 1996). Indeed, the plant food eaten by hunter-gatherers used to provide a $\mathrm{Ca}$ intake that, adjusted for differences in the body size, would have been in the range of $2000-4000 \mathrm{mg} / \mathrm{d}$ in adults (Eaton \& Nelson, 1991). This is why mechanisms to protect the organism from getting too much of this nutrient have been developed, while the obligatory $\mathrm{Ca}$ losses in sedentary adults on typical diets, through shed skin, nails, hair, sweat, urine and digestive secretions, are generally in the range of $160-240 \mathrm{mg} / \mathrm{d}$ (Heaney, 1999). Therefore, every strategy 
targeting an improvement in the Ca balance is very interesting. However, despite educational efforts and the increased availability of an array of Ca-fortified foods and supplements, intake of $\mathrm{Ca}$ remains inadequate. According to the results from the Third National Health and Nutrition Examination Survey in the USA (National Center for Health Statistics, 1994), Ca intakes among females are below the recommended levels after childhood, even when taking into account $\mathrm{Ca}$ from supplements (Looker, 2003). This is consistent with the data from the Continuing Survey of Food Intakes by Individuals, which reported that more than $70 \%$ of adult men and women in the United States have low dietary $\mathrm{Ca}$ intakes, the average being $657 \mathrm{mg} / \mathrm{d}$ (and $925 \mathrm{mg} / \mathrm{d}$ in males) after the age of nine (US Department of Agriculture, 1999). This is why increasing Ca intake was a primary objective in the Healthy People 2000 campaign and is still included in Healthy People 2010 recommendations (US Department of Health and Human Services, 2000). It has even been estimated that $\$ 2.6$ billion in direct medical cost would be spared if individuals over the age of fifty would consume about $1200 \mathrm{mg}$ of supplemental Ca (Bendich et al. 1999). Improving $\mathrm{Ca}$ intake is also highly recommended in Europe (Report from the European Community, 1999). Indeed, for example, in Italy, according to the Total Diet Study, daily Ca intake is only $76 \%$ of the average recommendation (LombardiBoccia et al. 2003). Again, over $50 \%$ of females aged 12-18 years in Ireland fail to achieve the recommended $\mathrm{Ca}$ intake, and in the UK $13-18 \%$ of $14-34$-year-olds and $8-15 \%$ of those over 65 years have habitual intakes below the reference (Van Dokkum, 1995). In the same way, in France, according to the INCA (2000) survey, Ca consumption is less than twothirds of the recommended dietary allowance in $20 \%$ of men, $30 \%$ of adolescents, $50 \%$ of female adolescents and $50 \%$ of men after the age of 65 years, and $75 \%$ of women after 55 years.

It is thus worthwhile to consider using a diet providing adequate amounts of $\mathrm{Ca}$ to decrease the rate of bone attrition. The dietary $\mathrm{Ca}$ deficiency may be addressed in different ways. The requirement for $\mathrm{Ca}$ relates to the size of its reserve, in other words, to the total bone mass, and this pool is limited (by the genetic and mechanical factors and the level of intestinal absorption), This means that the skeletal response will occur only when $\mathrm{Ca}$ is increased from the deficiency level to a threshold value above which there will be no further benefit from additional increases in intake. In this regard, $\mathrm{Ca}$ functions as a threshold nutrient. Furthermore, $\mathrm{Ca}$ intake may be inadequate for the straightforward reason that it is low; however even when intake is normal, it may still be inadequate because of subnormal absorption or greater than normal excretory loss. Indeed Ca bioavailability is frequently equated to its absorption, i.e. the first barrier.

In fact, given this low absorbability, the prospect of finding substances that might improve its bioavailability has enticed many scientists. However, ageing is associated with progressive reductions in the functional reserve that reflects a lack of successful response or adaptation to physiologic and physical perturbations. Thus, it seems highly likely that both age-related bone loss and the fracture burden of the elderly is partly due to the decline in $\mathrm{Ca}$ and vitamin D status. Among the main causes leading to impaired vitamin $\mathrm{D}$ status are reduced mucosal mass, low circulating $25(\mathrm{OH}) \mathrm{D}$ levels, partial intestinal resistance to $1,25(\mathrm{OH})_{2} \mathrm{D}$ and impaired renal conversion of $25(\mathrm{OH}) \mathrm{D}$ to $1,25(\mathrm{OH})_{2} \mathrm{D}$. This is why it is important to provide a wide array of options targeting an improvement in $\mathrm{Ca}$ retention. Few $\mathrm{Ca}$ absorption enhancers have been identified and the emerging evidence has shown that some non-digestible oligosaccharides could be an interesting tool.

\section{Inulin-type fructans, a way to improve bone health?}

\section{The process of $\mathrm{Ca}$ absorption}

Adequate consumption of $\mathrm{Ca}$ in conjunction with the optimisation of its absorption is likely to optimise bone mass. Actually, the major site of mineral absorption in man is the proximal small bowel through a saturable, transcellular pathway. During this process, luminal $\mathrm{Ca}^{2+}$ crosses the microvillar membrane and then translocates to the basolateral membrane of the enterocytes. It is then released by active transport into the general circulation. Intracellular diffusion is subject to physiological and nutritional regulation via vitamin $D$ that is involved in the biosynthesis of a cytosolic Ca-binding protein, calbindin $\mathrm{D}_{9 \mathrm{~K}}$.

Intestinal $\mathrm{Ca}$ absorption can also occur via a passive paracellular route, through the tight junctions between mucosal cells. It is non-saturable, concentration-dependent and occurs over the whole length of the small and large intestine. In fact, increasing paracellular absorption is promising because it is not limited by saturation; it is vitamin D-independent and occurs throughout the length of the intestine (Weaver \& Liebman, 2002). Indeed, there is increasing evidence that the colon can absorb nutritionally significant quantities of inorganic micronutrients (Trinidad et al. 1996; Younes et al. 1996) and this process may be susceptible to manipulation by fermentable substrates. In fact, these compounds help to achieve Ca homeostasis by shifting the major site of mineral absorption towards the large intestine (for a review, see Scholz-Arhens et al. 2001).

\section{Conceptual effects of inulin-type fructans on Ca absorption}

Fermentable substrates such as prebiotics can alter $\mathrm{Ca}$ absorption and thus modify its retention. According to the definition given by Gibson \& Roberfroid (1995), a prebiotic is 'a non-digestible food ingredient that beneficially affects the host by selectively stimulating the growth and/or activity of one or a limited number of bacteria in the colon, and thus improves host health'.

Inulin and oligofructose-type products have been investigated, so far, most extensively for their nutritional properties (for review, see Cashman, 2003). Classified as dietary fibres, they are natural constituents of many common foods including fruits, vegetables (artichoke contains $20-65 \%$ fructans on solid matter, asparagus $30 \%$, onions up to $50 \%)$ and cereals (1-4\% fructans in wheat flour). Their average daily consumption in the human diet reaches several grams (3-11 g in Europe; Van Loo et al. 1995). Inulin can also be industrially produced from chicory roots by hot water extraction, followed by refining and spray drying. The molecule consists of one moiety of glucose $(\mathrm{G})$ to which a number $(n$; the degree of polymerisation being 10 on average, ranging between 3 and 60) of fructose units (F) are bound by a $\beta$ bond, according to the $\mathrm{G}-\mathrm{F}_{n}$ chemical structure (Franck, 1998). Oligofructose $\left(\mathrm{G}-\mathrm{F}_{n}\right.$ and $\mathrm{F}_{n}$ chains) is a subset of inulin treated by a partial enzymatic hydrolysis, with a degree of polymerisation of about 4 (ranging from 2 to 8; Franck, 1998). This degree of polymerisation, as well as the solubility and the structural arrangement of the carbohydrates, are important for the rate of fermentation. 
Basically, it has been speculated that the stimulatory effect of inulin/oligofructose on mineral absorption is mainly due to their prebiotic character. Indeed, they are resistant to hydrolysis by small intestinal digestive enzymes, which are specific for $\alpha$ bonds, because of the $\beta$ configuration of the anomeric $\mathrm{C} 2$ in their fructose monomers that form $\beta 2-1$ glycosidic linkages (Roberfroid, 2002). This is why they are selectively fermented by the microflora in the human colon leading to a modulation of the composition of the natural ecosystem (dominated by bifidobacteria, while clostridia are decreased; Roberfroid, 1993; Roberfroid et al. 1998), a perceived health-promoting genus (Franck, 1998). They also exhibit dietary fibre effects by increasing the colonic biomass and, consequently, the stool weight and frequency (Roberfroid, 1997).

Their colonic fermentation produces SCFA (essentially acetate, propionate and butyrate) and other organic acids (e.g. lactate) that contribute to a lower luminal $\mathrm{pH}$ in the large intestine. Actually, $\mathrm{Ca}$ occurs in food as salts or is associated with other dietary constituents and it must be released in a soluble and probably ionised form before it can be absorbed. Consequently, the reduction in $\mathrm{pH}$ simply leads to a modification of its speciation and hence solubility in the luminal phase so that the bioavailable amount is increased (Rémésy et al. 1993; Ohta et al. 1995a). Passive diffusion of $\mathrm{Ca}$ in the intestinal part of the small intestine and the beginning of the large intestine is thus improved. It is also possible that SCFA contribute directly to the enhancement of $\mathrm{Ca}$ absorption via a cation exchange mechanism (increased exchange of cellular $\mathrm{H}^{+}$for luminal $\mathrm{Ca}^{2+}$; Lutz \& Scharrer, 1991). In fact, it has been shown that SCFA directly stimulated Ca disappearance across the colon in man more effectively than a solution containing $\mathrm{Ca}+\mathrm{NaCl}$, although the $\mathrm{pH}$ of the latter was lower (Trinidad et al. 1996).

Further, inulin and oligofructose may also modulate transcellular active $\mathrm{Ca}$ transport by altering the activity of vitamin $\mathrm{D}$ receptor and increasing calbindin $\mathrm{D}_{9 \mathrm{~K}}$ (the intracellular ferry protein involved in the translocation of $\mathrm{Ca}$ to the basolateral membrane of mucosal epithelial cells; Ohta et al. 1998a).

Another way to contribute to the enhanced mineral absorption is the increased production of butyrate and/or certain polyamines by which inulin and oligofructose might indirectly induce histological (cell growth) and functional (enhancement of the gut's absorptive area) changes in the intestinal epithelium (Roberfroid, 1993; Scholz-Arhens et al. 2001). However, according to data published by Scholz-Arens \& Schrezenmeier (2002), polyamines appear not to mediate this effect, although Rémésy et al. (1993) have shown that inulin is able to stimulate ornithine decarboxylase, the rate-limiting enzyme of polyamine synthesis.

Regarding the safety aspects of these molecules, no evidence of treatment-related toxicity, carcinogenicity or genotoxicity have been observed from the standard toxicity tests conducted at doses far above that anticipated for human exposure (the real issue being not that of safety, but rather that of gastro-intestinal intolerance, signs being demonstrated with intakes above 20-30 g; Hidaka et al. 1990).

\section{Inulin-type fructans and bone health: animal experiments}

Data on Ca balance

Molecules of interest. Various molecules such as oligofructose (Ohta et al. 1993, 1994, 1995b, 1998a,b,c; Taguchi et al. 1994;
Delzenne et al. 1995; Morohashi et al. 1998; Lopez et al. 2000; Takahara et al. 2000; Roberfroid et al. 2002; Scholz-Ahrens et al. 2002), inulin (Levrat et al. 1991), galactooligosaccharides (Chonan et al. 1995; Chonan \& Watanuki, 1996), lactulose (Brommage et al. 1993) or resistant starch (Schulz et al. 1993; Younes et al. 2001) have been studied.

Experimental models. As far as the experimental model is concerned, the stimulation of $\mathrm{Ca}$ absorption by inulin-type fructans was shown in young growing rats (Delzenne et al. 1995; Ohta et al. 1995a), or in animal models of disease or altered physiological status such as ovariectomy (Chonan et al. 1995), postgastrectomyanaemia (Ohta et al. 1998d), caecectomy (Brommage et al. 1993; Ohta et al. 1994b), or in Ca-, Mg- or Fe-deficient animals (Ohta et al. 1994a). Oligofructose has also been assessed in healthy dogs (Beynen et al. 2002).

Arising points. Inulin-type fructans exhibit a dose-dependent effect on Ca absorption. Levrat et al. (1991) showed that dietary inulin given in the range of $0-20 \%$ in the diet stimulated intestinal $\mathrm{Ca}$ absorption in a dose-dependent manner, coinciding with a progressive decrease in caecal or ileal $\mathrm{pH}$, hypertrophy of caecal walls and a rise in caecal pool of SCFA. In the same way, in the study carried out by Brommage et al. (1993), a near linear increase in $\mathrm{Ca}$ absorption was demonstrated in rats fed on 5 and $10 \%$ lactulose-containing diets. However, it has been shown that a diet supplemented with either $10 \%$ of inulin or oligofructose (Delzenne et al. 1995) or $5 \%$ of oligofructose or other non-digestible carbohydrates (Brommage et al. 1993) leads to a similar increase (about 60-65\%) in the apparent absorption of $\mathrm{Ca}$. Moreover, raising the content of oligofructose in the diet from 2.5 to $10 \%$ in ovariectomised rats showed a bone-sparing effect independent of the dose (Scholz-Ahrens et al. 2002)

The issue that dietary Ca content modulates the effect of inulintype fructans on Ca absorption has also been raised (Rémésy et al. 1993). In young growing rats, lactulose induced an increase in Ca absorption only if the diet contained $5 \mathrm{~g} \mathrm{Ca} / \mathrm{kg}$. No effect was seen when the dietary $\mathrm{Ca}$ content was $2 \mathrm{~g} / \mathrm{kg}$ (Brommage et al. 1993). In the same way, Chonan \& Watanuki (1996) reported a positive effect of the galactooligosaccharides on $\mathrm{Ca}$ absorption and bone content with a diet providing $5 \mathrm{~g} \mathrm{Ca} / \mathrm{kg}$, but not with a $0.5 \mathrm{~g} \mathrm{Ca} / \mathrm{kg}$ diet. Furthermore, Scholz-Ahrens et al. (2001) demonstrated a more prominent effect of oligofructose on Ca balance and bone trabecular structure in ovariectomised rats when $\mathrm{Ca}$ intake reached levels higher $(10 \mathrm{~g} \mathrm{Ca} / \mathrm{kg}$ diet $)$ than the dietary recommended levels of $5 \mathrm{~g} \mathrm{Ca} / \mathrm{kg}$ diet.

Finally, the issue of persistence of the effect is important to consider. The duration of most experimental studies is relatively short (between 14 and 28 d; Scholz-Ahrens et al. 2001; ScholzAhrens \& Schrezenmeir, 2002). Indeed, Brommage et al. (1993) reported a significant increase in Ca absorption on the first day of consumption of a diet providing $5 \%$ lactulose that disappeared after $7 \mathrm{~d}$, probably because of a down-regulation of the active transcellular route. On the other hand, apparent $\mathrm{Ca}$ absorption was still maintained over 4 weeks in the study performed by Ohta et al. (1998d) in gastrectomised rats. Similar results, in ovariectomised rats given a $5 \%$ oligofructose enriched food, were reported by Scholz-Ahrens et al. (2002).

Consequently, studies are necessary to prove that the benefits of these ingredients on $\mathrm{Ca}$ absorption persist in the longer-term. Nevertheless, the question of whether these effects can be translated into benefits to bone health must be highlighted. 


\section{Effects on bone health}

Parameters of bone turnover. Zafar et al. (2003) reported a slower bone turnover (both bone formation and resorption were decreased), together with an improved $\mathrm{Ca}$ balance in ovariectomised rats fed an inulin-type fructan-rich diet.

Bone mineral content/bone mineral density. In intact rats, supplementation with $5 \%$ of either galactooligosaccharide or oligofructose was shown to improve bone mineral content (BMC) (Chonan \& Watanuki, 1996). In the same way, in healthy rats, a $5 \%$ oligofructose diet was shown to enhance bone volume at the femoral metaphysis (Takahara et al. 2000). In addition, in growing male rats, consumption of 5 or $10 \%$ chicory inulin increased whole body BMC and BMD (Roberfroid et al. 2002). Finally, Kruger et al. (2003) have shown in the growing rat that various fructans, with different chain lengths, do not have the same impact on BMD.

In ovariectomised rats, an experimental model for postmenopausal osteoporosis, Taguchi et al. (1994) provided evidence for the prevention of osteopenia following surgery when $2 \cdot 5,2$ or $5 \%$ oligofructose was given. An improvement in bone ash weight and $\mathrm{Ca}$ content was highlighted in the study performed by Chonan et al. (1995) in ovariectomised animals fed a $5 \%$ galactooligosaccharides diet for 4 weeks. Still in ovariectomised rats, Scholz-Arhens et al. (2002) reported that, at the recommended Ca intake, a diet providing $10 \%$ oligofructose increased femur mineral levels, while the $5 \%$ oligofructose diet did so only on high Ca consumption.

In gastrectomised rats (and to a lesser extent in sham-operated animals), BMD was significantly higher in the femur and the tibia after treatment with oligofructose (Ohta et al. 1998d).

Bone microarchitecture. Scholz-Ahrens et al. (2002) demonstrated that in aged ovariectomised rats, oligofructose added to the diet for 8 weeks prevented the loss of trabecular bone induced by oestrogen deficiency (the effect becoming significant when the diet provided $1 \% \mathrm{Ca}$ ).

Bone strength. Zafar et al. (2003) failed to elicit a significant modulation of biomechanical femoral properties in ovariectomised rats exposed to a mixture of inulin + oligofructose, as shown by the lack of any change in the resistance to breaking forces, despite of a $5 \%$ increase in femoral Ca content.

In conclusion, dietary supplementation with inulin-type fructans enhances the uptake of $\mathrm{Ca}$, improves $\mathrm{BMC}$ in growing rats and alleviates the reduction in BMC and BMD that follows ovariectomy or gastrectomy in rats.

\section{Inulin-type fructans and bone health: clinical data}

Effect on Ca absorption. Man lacks a large self-contained caecum, a characteristic of the rat. However, limited information on the effects of fermentable polysaccharides on mineral absorption in human subjects suggests that fermentable carbohydrates may also stimulate $\mathrm{Ca}$ absorption.

Adolescents. Van den Heuvel et al. (1999a) fed twelve healthy adolescents (aged 14-16 years) orange juice supplemented with either $5 \mathrm{~g}$ oligofructose or $5 \mathrm{~g}$ sucrose three times daily over a period of $9 \mathrm{~d}$, in addition to their usual diet. They measured true fractional $\mathrm{Ca}$ absorption by a dual stable isotope technique on urine samples collected for $36 \mathrm{~h}$. A significant relative increase $(+10.8 \%)$ in the fractional $\mathrm{Ca}$ absorption was observed upon ingestion of oligofructose.

In the study by Griffin et al. (2002), sixty girls at or near menarche, with consumption of $\mathrm{Ca}$ approximating the recommended dietary intake $(1200-1300 \mathrm{mg} / \mathrm{d})$, were given either a relatively low amount of oligofructose $(8 \mathrm{~g} / \mathrm{d})$ or a mixture of oligofructose and inulin (oligofructose-enriched inulin) over 3 weeks. A $48 \mathrm{~h}$ urine collection was carried out after isotope administration so as to detect any modulatory effect on $\mathrm{Ca}$ absorption. No difference was seen with the oligofructose. On the other hand, while taking the oligofructose-enriched inulin, $\mathrm{Ca}$ absorption increased by $18 \%$ to an average of $494 \mathrm{mg}$ ( $v .416 \mathrm{mg}$ in the placebo group), i.e. an absolute daily increase in $\mathrm{Ca}$ absorption of $90 \mathrm{mg}$. Moreover, because no significant difference in urinary $\mathrm{Ca}$ excretion was demonstrated, it was suggested that the additional $\mathrm{Ca}$ that was absorbed was retained within the body.

To identify which subjects are most likely to benefit from consumption of inulin, a further study was carried out in fifty-four girls, aged 10-15 years, who were studied twice in random order after 4 weeks of adaptation to $8 \mathrm{~g}$ of oligofructose-enriched inulin or $8 \mathrm{~g}$ placebo, separated by a 2-week washout period. Again, the experimental diet significantly increased Ca absorption from $33.1 \%$ (SD 9.2\%) to $36.1 \%$ (SD 9.8\%). The most consistent identifiable determinant of a beneficial effect on $\mathrm{Ca}$ absorption was the fractional $\mathrm{Ca}$ absorption at baseline, with those individuals with lower absorption during placebo period showing the greatest benefit (Griffin et al. 2003).

Consequently, inulin-type fructans are able to improve $\mathrm{Ca}$ absorption in adolescents. If the absorbed extra $\mathrm{Ca}$ is deposited in bones, those molecules may help to optimise peak bone mass. Further long-term studies are thus necessary to assess this possibility.

Adults. In a pivotal study, Coudray et al. (1997) performed a balance study with nine healthy volunteers (mean age 25.5 years), who where given up to $40 \mathrm{~g}$ chicory inulin/d for a period of $26 \mathrm{~d}$, according to a crossover design ( $2 \mathrm{~d}$ of control diet followed by $14 \mathrm{~d}$ of progressive increase in inulin amount and then $12 \mathrm{~d}$ at maximal inulin consumption). Using the metabolic balance methodology, they found that upon inulin ingestion, apparent $\mathrm{Ca}$ absorption increased significantly from 21.3 \pm 12.5 to $33.7 \pm 12.1 \%$ (i.e. a $58 \%$ increase).

However, opposing this, a study carried out by Van den Heuvel et al. (1998) in healthy young adults found no significant differences in mineral absorption, irrespective of the treatment (which consisted of a constant basal diet supplemented for $21 \mathrm{~d}$ with $15 \mathrm{~g}$ inulin, oligofructose or galactooligosaccharides daily, or not supplemented). It was hypothesised that a $24 \mathrm{~h}$ period of urine collection, as used by Van den Heuvel et al. (1998), was too short to include the colonic component of $\mathrm{Ca}$ absorption and thus to make up a complete balance necessary to detect the effect of fructans.

Finally, in a very short-term study, fifteen young healthy women were given $210 \mathrm{mg}$ of $\mathrm{Ca}$ as cheese or as a supplement. In each case, the food was either enriched with $15 \mathrm{~g}$ inulin or without inulin (Teuri et al. 1999). Neither intact parathyroid hormone (PTH) nor ionised $\mathrm{Ca}$ and total $\mathrm{Ca}$ differed over $8 \mathrm{~h}$, whether inulin was consumed or not. However, measuring serum PTH and ionised Ca does not provide direct information about $\mathrm{Ca}$ absorption, as do isotope techniques. In addition, the length of the trial was probably too short.

Postmenopausal women. In a randomised, doubleblind, crossover design, Tahiri et al. (2003) investigated the medium-term effect ( 5 weeks separated by a 3 -week washout period) of a moderate daily dose $(10 \mathrm{~g})$ of oligofructose 
in twelve postmenopausal women. Oligofructose failed to show an effect on $\mathrm{Ca}$ absorption. However, the results from the subgroup of women who had been menopaused for more than 6 years suggest that this non-digestible carbohydrate may influence $\mathrm{Ca}$ absorption in the late postmenopausal phase.

In twelve older healthy women (of at least 5 years past the onset of menopause), Van den Heuvel et al. (1999b) investigated the effect of two doses of lactulose $(5$ and $10 \mathrm{~g} / \mathrm{d})$ given at breakfast for $9 \mathrm{~d}$ in a crossover design. Mean $\mathrm{Ca}$ absorption values during the treatments with 5 and $10 \mathrm{~g}$ lactulose were $30.0 \pm 7.6 \%$ and $32.2 \pm 7.0 \%$, respectively (against $27.7 \pm 7.7 \%$ in controls). The difference in absorption between the reference and the $10 \mathrm{~g}$ lactulose was significant.

In a similarly designed, double-blind, randomised, $9 \mathrm{~d}$ crossover trial in which postmenopausal women were given twice daily yoghurt drinks containing either transgalactooligosaccharides $(20 \mathrm{~g} / \mathrm{d})$ or sucrose, true $\mathrm{Ca}$ absorption was significantly increased by $16 \%(20 \cdot 6 \pm 7.0 \%$ to $23.9 \pm 6.9 \%$; Van den Heuvel et al. 2000$)$.

Finally, in a recent study, fifteen women (who were a minimum of 10 years past the onset of menopause and had taken no hormone replacement therapy for the past years) were treated with $10 \mathrm{~g}$ of oligofructose-enriched inulin daily for 6 weeks, according to a double-blind, placebo-controlled, crossover design (Holloway et al. 2004). True fractional Ca absorption, measured by dual isotopes before and after treatment, was significantly increased $(+7 \%)$.

These preliminary intervention studies have shown an improvement in $\mathrm{Ca}$ absorption in adolescents or young adults. In the same way, a positive effect has been reported in older women. Nevertheless, it remains to be demonstrated that the benefits of these ingredients on $\mathrm{Ca}$ absorption persist and can be translated into benefits to bone health.

Effects on bone health. In a clinical trial carried out on healthy young girls by Griffin et al. (2002), a significant increase in fractional and absolute $\mathrm{Ca}$ absorption was established after supplementation, while taking daily $1500 \mathrm{mg}$ of $\mathrm{Ca}$, in conditions where a further increase in $\mathrm{Ca}$ uptake is difficult to achieve. Assuming that this additional $\mathrm{Ca}$ would be retained daily during the 2 years of maximal adolescent bone mineral accumulation, the authors speculate that the net increase in bone mineral mass could be $65 \mathrm{~g}$, an average gain of $5.5 \%$. However, no change in the bone resorption was reported.

Tahiri et al. (2003) showed that plasma concentrations of total $\mathrm{Ca}$ and $\mathrm{PTH}$, as well as ${ }^{44} \mathrm{Ca}$ plasma enrichment remained identical during both the placebo and the oligofructose periods. Nevertheless, $1,25(\mathrm{OH})_{2} \mathrm{D}$ showed a tendency to decrease during oligofructose treatment and significantly decreased in the early menopause subgroup. Bone turnover was not modified.

On the other hand, according to Holloway et al. (L Holloway, S Moynihan and AL Friedlander, unpublished results), oligofructose-enriched inulin increased $\mathrm{Ca}$ absorption in volunteers who were at a minimum 10 years past the onset of menopause before starting the intervention nutrition trial. This 6-week treatment was able to affect markers of bone turnover (urinary deoxypyridinoline: $+1 \cdot 1 \mathrm{nmol} / \mathrm{mmol}$ creatinine; plasma osteocalcin: $+4.7 \mathrm{ng} / \mathrm{ml}$ ), even though this effect is difficult to interpret (Fig. 2). The results were even more pronounced (urinary deoxypyridinoline: $+1.7 \mathrm{nmol} / \mathrm{mmol}$ creatinine; plasma osteocalcin: $+6 \mathrm{ng} / \mathrm{ml}$ ) if the analysis was limited to volunteers who had an increased $\mathrm{Ca}$ and $\mathrm{Mg}$ absorption rate following intake of the experimental diet. Further the efficacy of treatment
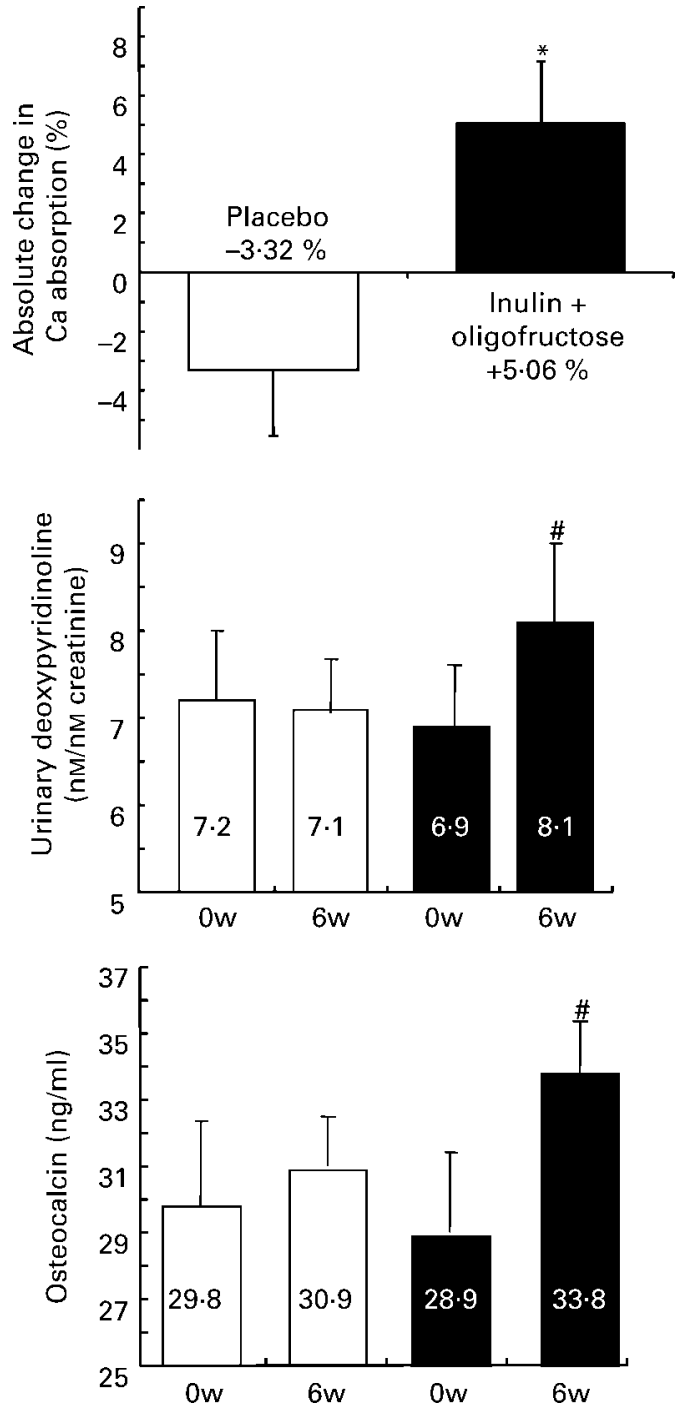

Fig. 2. Influence of a mixture of inulin + oligofructose (oligofructose-enriched inulin) on $\mathrm{Ca}$ absorption and markers of bone metabolism (urinary deoxypyridinoline and plasma osteocalcin) in postmenopausal women at baseline (0w) and after 6 weeks of supplementation $(6 \mathrm{w})$. *Significantly different from placebo; \#significantly different from baseline. Adapted from Hollaway et al. (L Holloway, S Moynihan and AL Friedlander, unpublished results).

seems to be higher in women with lower initial bone density of the spine.

To summarise, the modulation of $\mathrm{Ca}$ absorption in human subjects is quite consensual, although the parameters must be carefully chosen. Indeed plasma PTH or ionised Ca is not accurate enough to assess Ca absorption (Teuri et al. 1999). Moreover, the length of the period of urine collection is important. Van den Heuvel et al. (1998) failed to show any effect, probably because of experimental bias (it was hypothesised that a $24 \mathrm{~h}$ period of urine collection was too short to include the colonic component of Ca absorption). In the same way, Ellegärd et al. (1997) have measured the mineral balance in ileostomy volunteers, who were administered $15 \mathrm{~g}$ of either inulin or oligofructose daily. Data show that the intake of the fructans did not alter the $\mathrm{Ca}$ excretion at the end of the small intestine, probably because 
the modulation of mineral absorption by fructans must take place mainly in the colon.

As far as the question of whether the extra $\mathrm{Ca}$ absorbed is deposited in bones is concerned, there is no clear evidence in man. Longterm studies are needed. However, the impacted bone turnover recently reported by Holloway et al. (2004), when long-chain inulin and oligofructose were given together, opens a new area of investigation. Indeed, this mixture outperformed the traditional inulin and oligofructose with regard to $\mathrm{Ca}$ absorption, as well. In the same way, in adolescent girls, it increased the true Ca absorption by almost $20 \%$, while oligofructose alone had no significant effect (Griffin et al. 2002). Furthermore, in rats fed inulin-type fructans with different degrees of polymerisation (DP; oligofructose, DP 2-8; inulin, DP > 23; and a mixture of $92 \%$ inulin and $8 \%$ oligofructose), Kruger et al. (2003) assessed the retention of $\mathrm{Ca}$, femoral bone density, bone $\mathrm{Ca}$ content and excretion of collagen degradation products in the urine. These authors clearly show that the various inulin-type fructans do not have the same effect. Again, Coudray et al. (2003) compared different inulintype fructans that differ in the sugar chain length and in chain branching and found a synergistic effect with the combination of inulin-type fructans with different chain lengths in adult male rats. A potential mechanism for the improved efficiency could be the distribution of the chain lengths resulting in different fermentation profiles of the mixture (especially oligofructose-enriched inulin) that might be critical to obtain maximum efficacy at low daily doses. Actually, the short-chain components such as oligofructose are likely to be most active in the proximal part of the colon (where they can serve as a starter for selective bifidogenic fermentation), while the long-chain molecules could have their effect in the distal part (where they can maintain the metabolic activity of the improved flora). Combining both types of molecules in one product offers a synergistic effect on $\mathrm{Ca}$ absorption because the fermentation process takes place over the full length of the colon, thus maximising the mucosal surface through which the extra-solubilised Ca can migrate (Fig. 3).

Finally, inulin-type fructans have failed to modulate Ca absorption during the first 5 years after the onset of menopause. Indeed, this period is predominantly characterised by hormonal disturbances and it is apparently difficult to modulate $\mathrm{Ca}$ metabolism variables during that period (increased $\mathrm{Ca}$ intake is not effective in retarding bone loss in early postmenopausal women). However, inulin-type fructans still remain as candidates for putative innovative dietary health intervention to prevent postmenopausal osteoporosis.

The case for postmenopausal osteoporosis prevention. Albright \& Reifenstein (1948) have underlined the importance of sex steroids in maintenance of skeletal integrity. Today, an overwhelming body of evidence emphasises that gonadal failure at the time of menopause is the dominating pathogenic factor for osteoporosis and that the administration of oestrogens in postmenopausal women prevents this loss, as long as use is continued. In fact, it has been established that acute ovarian deficiency would account for the loss of about $20 \%$ of bone mass in the first 5-7 years of menopause (Avioli \& Lindsay, 1990). This is why hormone replacement therapy was the mainstay for the prevention of bone loss in postmenopausal women. However, prophylaxis is currently limited to only a very small minority of eligible women, due to a number of factors that are unlikely to be resolved in the near future (mainly, associated side-effects). This is the reason why scientists have targeted phytooestrogen consumption as a possible way to achieve this goal, substantiating their importance based on emerging data which support a potential preventive effect for a range of hormone-dependent conditions (Setchell \& Lydeking-Olsen, 2003).

Phyto-oestrogens belong to a broad group of plant-derived compounds called polyphenols that can behave as oestrogen
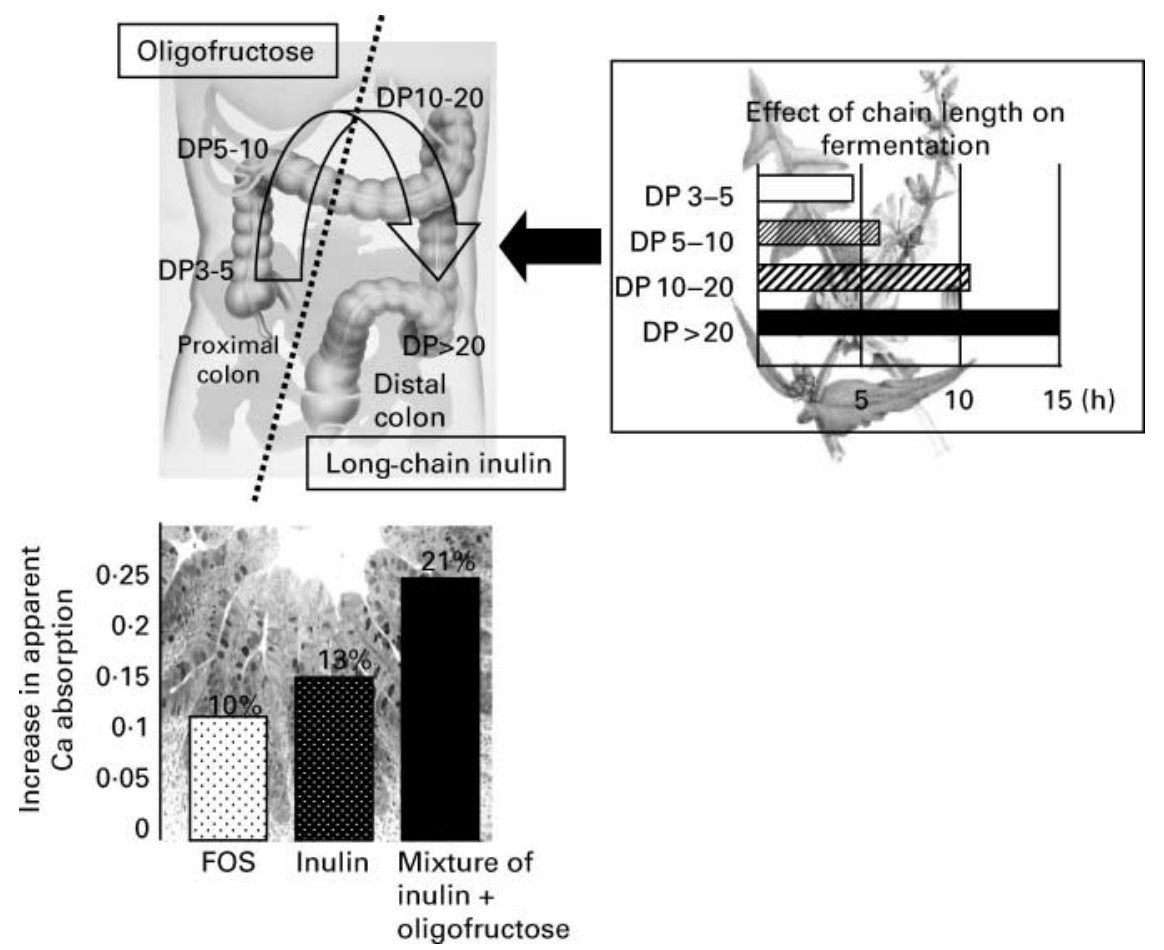

Fig. 3. Influence of different types of fructans (FOS, fructooligosaccharides) that differ in sugar chain length (DP, degree of polymerisation) and in chain branching on $\mathrm{Ca}$ absorption in adult rats (adapted from Coudray et al. 2003) and hypothesis of the mechanisms of action. 
mimics. The most studied molecules are the isoflavones, mainly found in soya or soya products. Conspicuous features of their non-steroidal chemical structure are the phenolic ring which is theoretically a prerequisite for oestrogenic activity (binding to the oestrogen receptor; Setchell, 1998) and a pair of hydroxyl groups, one being a phenol function on an aromatic A ring, while the second lies at the opposite end (Miksicek, 1993). These molecules are receiving great scrutiny as food supplements for the purpose of preventing osteoporosis because, although this condition universally affects all races and nationalities, conspicuous differences may be encountered in the severity of its manifestations, with a weaker effect in Asian countries (Cooper et al. 1992; Ling et al. 1996). Moreover, most observational studies have provided evidence that postmenopausal women consuming the highest amounts of soya foods (and hence isoflavones) have the highest BMD, measured either on the femur or on the spine (for review, see Setchell \& Lydeking-Olsen, 2003). Some dietary intervention trials targeting BMD as the main outcome have also shown a bone-sparing effect (Dalais et al. 1998; Potter et al. 1998; Alekel et al. 2000; Lydeking-Olsen et al. 2002; Morabito et al. 2002).

More interestingly, Setchell et al. (2002) have hypothesised that intestinal metabolism of isoflavones could be the most important clue to the clinical efficacy of soya foods in preventing osteopenia. In fact, inulin-type fructans may have a beneficial effect on isoflavone metabolism because, as phyto-oestrogens mainly occur in plants as glycosides, they have to be hydrolysed (the glycosidic bonds have to be broken down) before intestinal
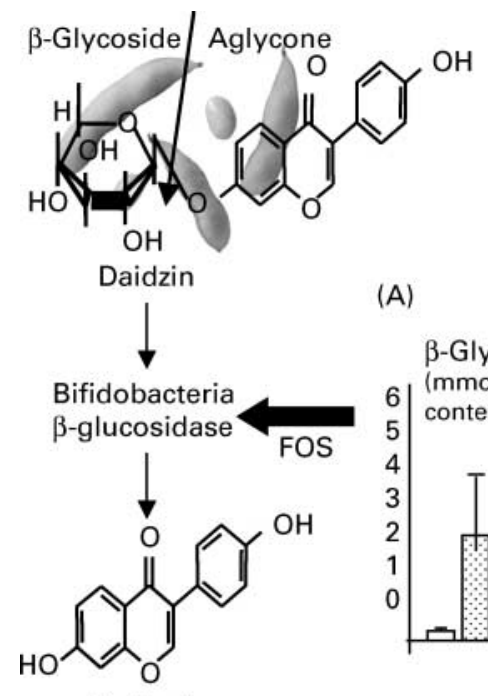

(A)
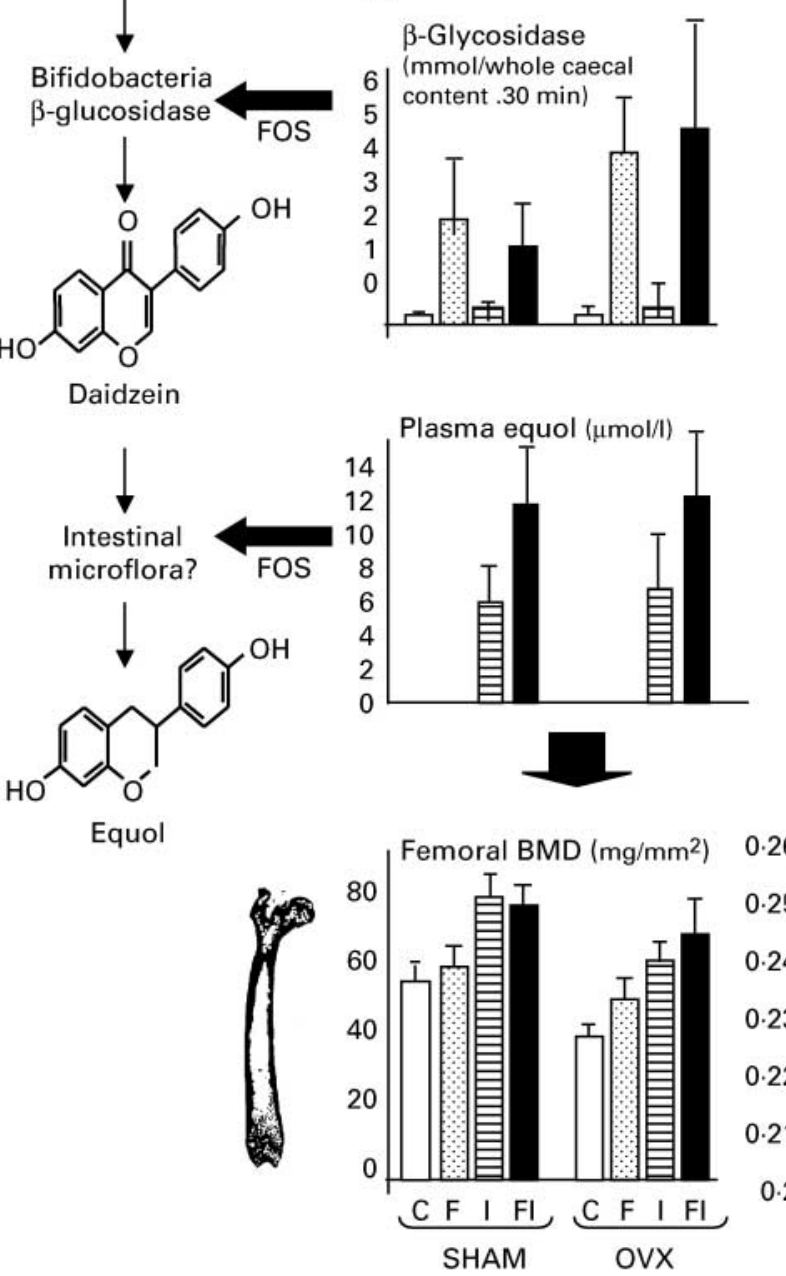

(B)
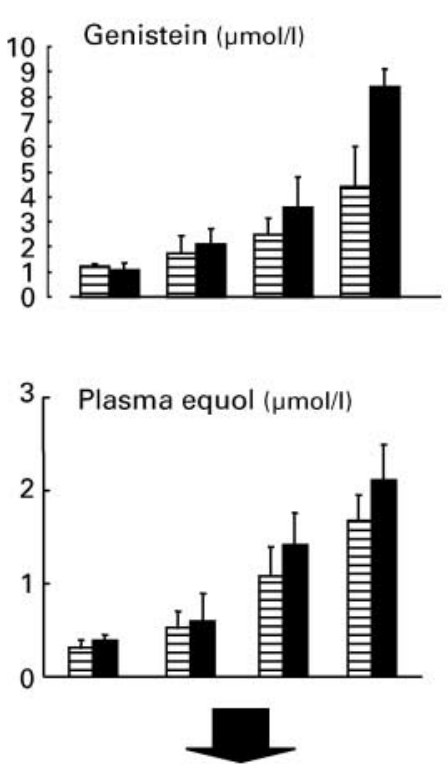

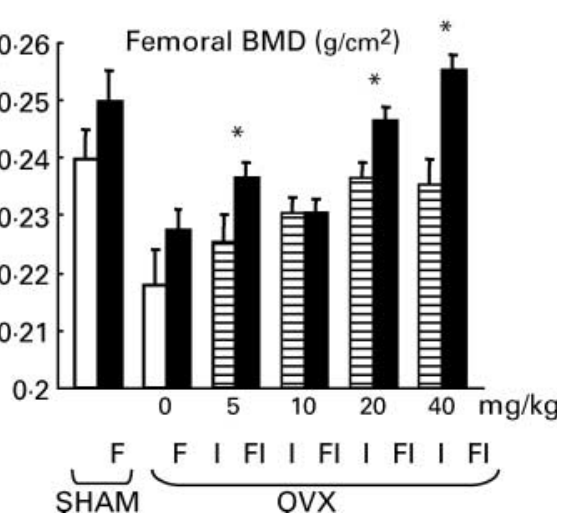

Fig. 4. Influence of isoflavones (I) given alone (at $0,5,10,20$ or $40 \mathrm{mg} / \mathrm{kg}$ ) or together with oligofructose (F; IF) on markers for isoflavones metabolism and on bone mineral density (BMD). FOS, fructooligosaccharides; C, control; OVX, ovariectomised. (A) Adapted from Ohta et al. (2002) for mice; (B) adapted from Mathey et al. (2003) for the rat. 
absorption, glucosidases of intestinal bacteria such as lactobacilli, bacteroides and bifidobacteria being involved in this process. It has been shown that dietary oligofructose may increase $\beta$-glucosidase activity in the large intestine, leading to an enhancement of the large intestinal absorption of these compounds (Uehara et al. 2001). The clearance of isoflavones is thus prolonged. Besides, phyto-oestrogens (and more especially daidzein) can be further metabolised to be converted into a more potent molecule, equol. However, on average, this bacterial metabolite is found in only $45 \%$ of the postmenopausal women studied (Axelson et al. 1982). Equol has a longer half-life and a much higher affinity for the oestrogen receptor than its precursor (daidzein) and has the highest antioxidation capacity among isoflavones (Setchell et al. 2002). This could explain the preliminary results from a 2year study carried out in postmenopausal women randomised to consume $500 \mathrm{ml}$ of soyamilk either with or without isoflavones. Greater effects on bone health were elicited when volunteers were able to produce equol, a $2.4 \%$ increase in the lumbar spine BMD being demonstrated, compared to the control group, while no significant difference was shown in the non-producers (Lydeking-Olsen et al. 2002).

Thus, because a greater efficacy of phyto-oestrogens can be expected if converted into equol by the intestinal microflora, there is a good rationale for considering non-digestible carbohydrates as a tool to target an increase in isoflavones bioavailability. Indeed, it has been established that concurrent dietary intake, in particular high dietary fibre, exerts a major influence on isoflavone metabolism (Xu et al. 1994).

In fact, in ovariectomised mice (Ohta et al. 2002) or rats (Mathey et al. 2003), two experimental models for postmenopausal osteoporosis, oligofructose consumption has been shown to increase the bone-sparing effect of isoflavones by improving equol production (Fig. 4). The lower response regarding the impact on equol production in the rat experiment could probably be explained by the fact that this animal is a spontaneously good producer of equol. Thus, even though these results are too few to draw final conclusions, they appear very provocative.

\section{Conclusion}

In conclusion, programmes for the prevention of osteoporosis need to be implemented. A focus on behaviour modification must be adopted by societies to effectively lower incidence rates of hip fractures in the future generations.

Adequate Ca intake from childhood until the end of life is critical for the formation and retention of a healthy skeleton. Beyond $\mathrm{Ca}$ intake, Ca bioavailability is also an important parameter in terms of bone health. Because inulin-type fructans can modulate $\mathrm{Ca}$ absorption, it is thus of great interest to still ascertain their impact on bone physiology in adolescents and the elderly. Indeed, studies are necessary to prove that the benefits of these ingredients to $\mathrm{Ca}$ absorption persist in the longer-term and that they can be translated into benefits to bone health.

Furthermore, because a dietary combination of oligofructose and isoflavones may have a potential promise for maintaining or improving bone mass in experimental animal models for postmenopausal osteoporosis, we also need to gather more data targeting bone metabolism in postmenopausal women before health professionals can actively advocate the increased consumption of inulin-type fructans.

\section{Acknowledgement}

The author wishes to acknowledge Marcel Roberfroid (Université Catholique de Louvain, Belgium) and Anne Franck (Orafti, Belgium) for their help with bibliography.

\section{References}

Albright F \& Reifenstein EC (1948) Metabolic bone disease; osteoporosis. In The Parathyroid Glands and Metabolic Bone Disease, pp. 145-204 [F Albright and EC Reifenstein, editors]. Baltimore: Williams \& Wilkins.

Alekel DL, Germain A St, Peterson CT, Hanson KB, Stewart JW \& Toda $\mathrm{T}$ (2000) Isoflavone-rich soy protein isolate attenuates bone loss in the lumbar spine of perimenopausal women. Am J Clin Nutr 72, 844-852.

Aloia JF, Vaswani A, Yeh JK, Ross PL, Flaster E \& Dilmanian FA (1994) Calcium supplementation with and without hormone replacement therapy to prevent postmenopausal bone loss. Ann Intern Med 120, 97-103.

Anderson JJB, Rondano P \& Holmes A (1996) Nutrition, life style and quality of life. Scand J Rheumatol 25, Suppl., 65-74.

Andon M, Lloyd T \& Matkovic V (1994) Supplemental trials with Ca citrate malate: evidence in favour of increasing the Ca RDA during childhood and adolescence. J Nutr 14, 17S

Avioli LV \& Lindsay R (1990) The female osteoporotic syndrome (s). In Metabolic Bone Disease and Clinically Related Disorders, pp. 397-451 [LV Avioli and SM Krane, editors]. Philadelphia: WB Saunders Company.

Axelson M, Kirk DN, Farrant RD, Cooley G, Lawson AM \& Setchell KDR (1982) The identification of the weak oestrogen equol (7-hydroxy-3-(4'-hydroxyphenyl)chroman) in human urine. Biochem $J$ 201, 353-357.

Baran D, Sorenson A, Grimes J, Lew R, Karellas A, Johnston B \& Roche J (1990) Dietary modification with dairy products for preventing vertebral bone loss in premenopausal women: a three year prospective study. J Clin Endocrinol Metab 70, 264-270.

Bendich A, Leader S \& Muhuri P (1999) Supplemental Ca for the prevention of hip fracture: potential health economic benefits. Clin Ther 21, 1058-1072.

Beynen AC, Baas JC, Hoekemeijer PE, Kappert HJ, Bakker MH, Koopman JP \& Lemmens AG (2002) Faecal bacterial profile, nitrogen excretion and mineral absorption in healthy dogs fed supplemental oligofructose. J Anim Physiol Anim Nutr 86, 298-305.

Bonjour JP \& Rizzoli R (1996) Bone acquisition in adolescence. In Osteoporosis, pp. 445-476 [R Marcus, D Feldman and J Kelsey, editors]. San Diego: Academic Press.

Bonjour JP, Carrie AL, Ferrari S, Clavien H, Slosman D \& Theintz G (1997) Calcium-enriched foods and bone mass growth in prepubertal girls: a randomized, double blind, placebo-controlled trial. J Clin Invest 99, 1287-1294.

Brommage R, Binacua C, Antille S \& Carrié AL (1993) Intestinal Ca absorption in rats is stimulated by dietary lactulose and other resistant sugars. J Nutr 123, 2186-2194.

Cadogan J, Eastell R, Jones N \& Barker ME (1997) Milk intake and bone mineral acquisition in adolescent girls: randomised, controlled intervention trial. Br Med J 315, 1255-1260.

Cashman KD (2002) Calcium intake, Ca bioavailability and bone health. Br J Nutr 87, Suppl., S169-S177.

Cashman KD (2003) Prebiotics and Ca bioavailability. Curr Issues Intest Microbiol 4, 21-32.

Chan GM, Hoffman K \& McMurry M (1995) Effects of dairy products on bone and body composition in pubertal girls. $J$ Pediatr 126, 551-556.

Chapuy MC, Arlot ME, Duboeuf F, Brun J, Crouzet B, Anaud S, Delmas PD \& Meunier PJ (1992) Vitamin D3 and Ca to prevent hip fractures in the elderly women. $N$ Engl J Med 327, 1637-1642. 
Chapuy MC, Arlot ME, Delmas PD \& Meunier PJ (1994) Effect of Ca and cholecalciferol treatment for three years on hip fractures in elderly women. Br Med J 308, 1081-1082.

Chevalley T, Rizzoli R, Nydegger V, Slosman D, Rapin CH, Michel JP, Vasey H \& Bonjour JP (1994) Effects of Ca supplements on femoral bone mineral density and vertebral fracture rate in vitamin $\mathrm{D}$ replete elderly patients. Osteoporos Int 4, 245-252.

Chonan O \& Watanuki M (1996) The effect of 6 -galactooligosaccharides on bone mineralization of rats adapted to different levels of dietary Ca. Int J Vitam Nutr Res 66, 244-249.

Chonan O, Matsumoto K \& Watanuki M (1995) Effect of galactooligosaccharides on $\mathrm{Ca}$ absorption and preventing bone loss in ovariectomized rats. Biosci Biotechnol Biochem 59, 236-239.

Consensus Development Conference (1993) Diagnosis prophylaxis and treatment of osteoporosis. J Am Med Assoc 94, 646-650.

Consensus Development Statement (1997) Who are candidates for prevention and treatment for osteoporosis? Osteoporos Int 7, 1-6.

Cooper C, Campion G \& Melton LJ (1992) Hip fractures in the elderly. A world wide projection. Osteoporos Int 2, 285-289.

Coudray C, Bellanger J, Castiglia-Delavaud C, Rémésy C, Vermorel M \& Rayssiguier Y (1997) Effect of soluble or partly soluble dietary fibres supplementation on absorption and balance of $\mathrm{Ca}$, magnesium, iron, and zinc in healthy young men. Eur J Clin Nutr 151, 375-380.

Coudray C, Tressol JC, Gueux E \& Rayssiguier Y (2003) Effects of inulin-type fructans of different chain length and type of branching on intestinal absorption and balance of $\mathrm{Ca}$ and magnesium in rats. Eur J Nutr 42, 91-98.

Coxam V \& Horcajada MN (2004) Prevention nutritionnelle de l'ostéoporose, pp. 1-166. Paris: Lavoisier editions.

Cumming RG (1990) Calcium intake and bone mass: a quantitative review of the evidence. Calcif Tissue Int 47, 194-201.

Cumming RG \& Nevitt MC (1997) Calcium for prevention of osteoporotic fractures in postmenopausal women. J Bone Miner Res 12, 1321-1329.

Cumming RG, Cummings SR, Nevitt MC, Scott J, Ensrud KE, Vogt TM $\&$ Fox K (1997) Calcium intake and fracture risk: results from the study of osteoporotic fractures. Am J Epidemiol 145, 926-934.

Cummings SR, Kelsey JL, Nevitt MC \& O’Dowd KJ (1985) Epidemiology of osteoporosis and osteoporotic fractures. Epidemiol Rev 7, 178-208.

Dalais FS, Rice GE, Bell RJ, Murkies AL, Medley G, Staruss BJG \& Wahlqvist ML (1998) Dietary soy supplementation increases vaginal cytology maturation index and bone mineral content in postmenopausal women. Am J Clin Nutr 68, Suppl., 1518S.

Dawson-Hughes B (1991) Calcium supplementation and bone loss: a review of controlled clinical trials. Am J Clin Nutr 54, 274S-280S

Dawson-Hughes B, Dallal GE, Krall A, Sadowki L, Sahyoun N \& Tannenbaum S (1990) A controlled trial of the effect of Ca supplementation on bone density in post-menopausal women. $\mathrm{N} \mathrm{Engl}$ $J$ Med 323, 878-883.

Dawson-Hughes B, Harris SS, Krall EA \& Gerard ED (1997) Effect of Ca and vitamin D supplementation on bone density in men and women 65 years of age or older. $N$ Engl J Med 337, 670-676.

Delzenne N, Aertssens J, Verplaetse H, Roccaro M \& Roberfroid M (1995) Effect of fermentable fructo-oligosaccharides on mineral, nitrogen and energy digestive balance in the rat. Life Sci 57, 1579-1587.

Devine A, Criddle RA, Dick IM, Kerr DA \& Prince RL (1995) A longitudinal study of the effect of sodium and $\mathrm{Ca}$ intakes on regional bone density in postmenopausal women. Am J Clin Nutr 62, 740-745.

Eaton SB \& Nelson DA (1991) Calcium in evolutionary perspective. Am J Clin Nutr 54, 281S-287S.

Elders PJ, Netelembos JC, Lips P, Van Ginkel FC, Khoe E, Leewenkamp OR, Hackeng WH \& Van der Stelt (1994) Calcium supplementation reduces vertebral bone loss in perimenopausal women: a controlled trial in 248 women between 46 and 55 years of age. J Clin Endocrinol Metab 73, 533-540.

Ellegärd L, Andersson H \& Bosaeus I (1997) Inulin and oligofructose do not influence the absorption of cholesterol, and the excretion of cholesterol, $\mathrm{Fe}, \mathrm{Ca}, \mathrm{Mg}$ and bile acids but increases energy excretion in man. A blinded controlled cross-over study in ileostomy subjects. Eur J Clin Nutr 51, 1-5.

Franck A (1998) Prebiotics stimulate $\mathrm{Ca}$ absorption: a review. Milchwissenschaft 53, 427-429.

Gibson G \& Roberfroid M (1995) Dietary modulation of the human colonic microflora: introducing the concept of prebiotics. J Nutr 125, 1401-1412.

Griffin IJ, Davila PM \& Abrams SA (2002) Non-digestible oligosaccharides and $\mathrm{Ca}$ absorption in girls with adequate $\mathrm{Ca}$ intakes. Br J Nutr 87, S187-S191.

Griffin IJ, Hicks PMD, Heaney RP \& Abrams SA (2003) Enriched chicory inulin increases $\mathrm{Ca}$ absorption mainly in girls with lower $\mathrm{Ca}$ absorption. Nutr Res 23, 901-909.

Heaney RP (1996) Nutrition and risk for osteoporosis. In Osteoporosis, pp. 483-509 [R Marcus, D Feldman and J Kelsey, editors]. San Diego: Academic Press.

Heaney R (1999) Aging and Ca balance. In The Aging Skeleton, pp. 19-26 [C Rosen, J Glowacki and JP Bilezikian, editors]. San Diego: Academic Press.

Heaney RP (2003) Long-latency deficiency disease: insights from Ca and vitamin D. Am J Clin Nutr 78, 912-919.

Hidaka H, Hirayama M, Tokunaga T \& Eida T (1990) The effects of undigestible fructooligosaccharides on intestinal microflora and various physiological functions on human health. Adv Exp Med Biol 270, $105-117$.

Holbrook TL, Barrett-Connor E \& Windgard DL (1988) Dietary Ca and risk of hip fracture: 14 year prospective population study. Lancet ii, $331-335$.

Holloway L, Moynihan S, Kent K, Hsu AR \& Friedlander AL (2004) Effects of oligofructose enriched inulin on mineral absorption and markers of bone turnover in postmenopausal women. Am J Clin Nutr (In Press).

INCA (2000) Enquête INCA individuelle et nationale sur les consommations alimentaires, pp. 1-158 [JL Volatier, coordonnateur]. Paris: Editions Tec \& Doc.

Johnston CC, Miller JZ, Slemenda CW, Reister TK, Hui S, Christian JC \& Peacock M (1992) Calcium supplementation and increases in bone mineral density in children. $N$ Engl J Med 327, 82-87.

Kanis J, Johnell O, Gullborg B, et al. (1992) Evidence for efficacy of drugs affecting bone metabolism in preventing hip fractures. $\mathrm{Br} \mathrm{Med}$ $J$ 305, 1124-1128.

Kruger MC, Brown KE, Collett G, Layton L \& Schollum LM (2003) The effect of fructooligosaccharides with various degrees of polymerisation on Ca bioavailability in the growing rat. Exp Biol Med 228, 683-688.

Lee WTK, Leung SSF, Lui SSH \& Lau J (1993) Relationship between long term $\mathrm{Ca}$ intake and bone mineral content of children aged from birth to 5 years. Br J Nutr 70, 235-248.

Lee WTK, Leung SSF, Wang SH, Xu YC, Zeng WP, Lau J, Oppenheimer SJ \& Cheng JC (1994) Double blind, controlled Ca supplementation and bone mineral accretion in children accustomed to a low-Ca diet. Am J Clin Nutr 60, 744-750.

Levrat MA, Rémésy C \& Demigné C (1991) High propionic acid fermentations and mineral accumulation in the cecum of rats adapted to different levels of inulin. J Nutr 121, 1730-1737.

Ling X, Aimin L, Xine Z, Xiaoshu C \& Cummings S (1996) Very low rates of hip fracture in Beijing, People's Republic of China. Am J Epidemiol 144, 901-907.

Lloyd T, Andon MB, Rollings N, Martel JK, Landis JR, Demers LM, Eggli DF, Kieselhorst \& Kulin HE (1993) Calcium supplementation and bone mineral density in adolescent girls. J Am Med Assoc 270, $841-844$.

Lombardi-Boccia G, Aguzzi A, Cappelloni M, Di Lullo G \& Lucarini M (2003) Total-diet study: dietary intakes of macro elements and trace elements in Italy. Br J Nutr 90, 1117-1121.

Looker AC (2003) Interaction of science, consumer practices and policy: Ca and bone health as a case study. J Nutr 133, 1987S-1991S 
Lopez HW, Coudray C, Levrat-Verny MA, Feillet-Coudray C, Demigné C \& Rémésy C (2000) Fructooligosaccharides enhance mineral apparent absorption and counteract the deleterious effects of phytic acid on mineral homeostasis in rats. $J$ Nutr Biochem 11, 500-508.

Lutz T \& Scharrer F (1991) The effect of SCFA on Ca absorption by the rat colon. Exp Physiol 76, 615-618.

Lydeking-Olsen E, Jensen JBE, Setchell KDR, Damhus M \& Erdman JW (2002) Isoflavone-rich soymilk prevents bone-loss in the lumbar spine of postmenopausal women. A 2 year study. J Nutr 132, $581 \mathrm{~S}$

MacDonald HM, New SA, Golden MHN, Campbell MK \& Reid D (2004) Nutritional associations with bone loss during the menopausal transition: evidence of a beneficial effect of $\mathrm{Ca}$, alcohol, and fruit and vegetable nutrients and of a detrimental effect of fatty acids. Am J Clin Nutr 79, 155-165.

Mathey J, Katicoulibali S, Puel C, Bennetau C, Lebecque P, Davicco MJ, Horcajada MN, Garel JM \& Coxam V (2003) Dietary fructooligosaccharides improve soy-osteopenia prevention in the ovariectomised rat. J Bone Miner Res 18, Suppl., S266.

Matkovic V, Kostial K, Simonovic, Buzina R, Brodarec A \& Nordin BE (1979) Bones status and fracture rates in two regions of Yugoslavia. Am $J$ Clin Nutr 32, 540-549.

Matkovic V, Fontana D, Tominac C, Goel P \& Chesnut CH (1990) Factors that influence peak bone mass formation: a study of $\mathrm{Ca}$ balance and the inheritance of bone mass in adolescent females. Am J Clin Nutr 52, $878-888$.

Mertz W (2000) Three decades of dietary recommendations. Nutr Rev 58, 324-331.

Miksicek RJ (1993) Commonly occurring flavonoids have estrogenic activity. Mol Pharmacol 44, 37-43.

Morabito N, Crisafulli A, Vergara C, et al. (2002) Effects of genistein and hormone-replacement therapy on bone loss in early postmenopausal women: a randomized double-blind placebo-controlled study. J Bone Miner Res 17, 1904-1912.

Morohashi T, Sano T, Ohta A \& Yamada S (1998) True Ca absorption in the intestine is enhanced by fructooligosaccharides feeding in the rat. J Nutr 128, 1815-1818.

National Center for Health Statistics (1994) Plan and operation of the Third National Health and Nutrition Examination Survey, 1988-1994. Vital and Health Statistics 1. DHHS Publication no. (PHS) 94-1308. Hyattsville: NCHS.

Nelson ME, Fisher EC, Dilmanian FA, Dallal GE \& Evans WJ (1991) A 1-y walking program and increased dietary $\mathrm{Ca}$ in postmenopausal women: effects on bone. Am J Clin Nutr 53, 1304-1311.

Ohta A, Osakabe N, Yamada K, Saito Y \& Hidaka H (1993) Effect of fructooligosaccharides and other saccharides on $\mathrm{Ca}, \mathrm{Mg}$ and $\mathrm{P}$ absorption in rats. J Jpn Soc Nutr Food Sci 46, 123-129.

Ohta A, Baba S, Takizawa T \& Adachi T (1994a) Effects of fructooligosaccharides on the absorption of magnesium in the magnesium-deficient rat model. J Nutr Sci Vitaminol 40, 171-180.

Ohta A, Ohtsuki M, Takizawa T, Inaba H, Adachi T \& Kimura S (1994b) Effects of fructooligosaccharides on the absorption of magnesium and Ca by cecectomized rats. Int J Vitam Nutr Res 64, 316-323.

Ohta A, Ohtsuki M, Baba S, Adachi T, Sakata T \& Sakaguchi EI (1995a) Calcium and magnesium absorption from the colon and rectum are increased in rats fed fructo-oligosaccharides. $J$ Nutr 125, 2417-2424.

Ohta A, Ohtsuki M, Baba S, Takizawa T, Adachi T \& Kimura S (1995b) Effects of fructooligosaccharides on the absorption of iron, calcium and magnesium in iron-deficient anemic rats. J Nutr Sci Vitaminol 41, 281-291.

Ohta A, Motohashi K, Ohtsuki M, Hirayama M, Adachi T \& Sakuma K (1998a) Dietary fructooligosaccharides change the intestinal mucosal concentration of calbindin-D9K in rats. $J$ Nutr 128, 934-939.

Ohta A, Ohtsuki M, Baba S, Hirayama M \& Adachi T (1998b) Comparison of the nutritional effects of fructo-oligosaccharides of different sugar chain lengths in rats. Nutr Res 18, 109-120.
Ohta A, Ohtsuki M, Hosono A, Adachi T, Hara H \& Sakata T (1998c) Dietary fructooligosaccharides prevent osteopenia after gastrectomy in rats. $J$ Nutr 128, 106-110.

Ohta A, Ohtsuki M, Uehara M, Hosono A, Hirayama M, Adachi T \& Hara H (1998d) Dietary fructooligosaccharides prevent postgastrectomy anemia and osteopenia in rats. J Nutr 128, 485-490.

Ohta A, Uehara M, Sakai K, Takasaki M, Adlercreutz H, Morohashi T \& Ishimi Y (2002) A combination of dietary fructooligosaccharides and isoflavones conjugates increases femoral bone mineral density and equol production in ovariectomized mice. $J$ Nutr 132, 2048-2054.

Polley KJ, Nordin BEC, Baghurst PA \& Walker CJ (1987) Effect of Ca supplementation on forearm bone mineral content in postmenopausal women: a prospective sequential controlled trial. $J$ Nutr 117, $1929-1935$.

Potter SM, Baun JA, Teng H, Stillman RJ, Shay NF \& Erdman JW (1998) Soy protein and isoflavones: their effects on blood lipids and bone density in postmenopausal women. Am J Clin Nutr 68, 1375-1379.

Prentice A (1997) Is nutrition important in osteoporosis? Proc Nutr Soc 56, 357-367.

Prince R, Devine A, Dick I, Criddle A, Kerr D, Kent N, Price R \& Randell A (1995) The effects of Ca supplementation (milk powder or tablets) and exercise on bone density in postmenopausal women. $J$ Bone Miner Res 10, 1068-1075.

Recker RR, Hinders S, Davies KM, Heaney RP, Stegman MR, Lappe JM \& Kimmel DB (1996) Correcting Ca nutritional deficiency prevents spine fractures in elderly women. J Bone Miner Res 11, 1961-1996.

Reid DM \& New SA (1997) Nutritional influences on bone mass. Proc Nutr Soc 56, 977-987.

Reid IR, Ames RW, Evans MC, Gamble GD \& Sharpe SJ (1993) Effect of Ca supplementation on bone loss in postmenopausal women. $N$ Engl $J$ Med 328, 460-464.

Reid IR, Ames RW \& Evans MC (1995) Long-term effects of Ca supplements on bone loss and fractures in postmenopausal women: a randomized controlled trial. Am J Med 98, 331-335.

Rémésy C, Levrat MA, Gamet L \& Demigné C (1993) Cecal fermentations in rats fed oligosaccharides (inulin) are modulated by dietary Ca level. Am J Physiol 264, G855-G862.

Report from the European Community (1999). Building strong bones and preventing fractures. Summary report on osteoporosis in the European Community - Action for prevention. Brussels: European Commission.

Rico H, Revilla M, Villa LF, Alvarez de Buergo M \& Arribas I (1994) Longitudinal study on the effect of Ca pidolate on bone mass in eugonadal women. Calcif Tissue Int 54, 477-480.

Riis B, Thompsen K \& Christiansen C (1987) Does Ca supplementation prevent postmenopausal bone loss? N Engl J Med 316, 173-177.

Roberfroid M (1993) Dietary fibers, inulin, and oligofructose: a review comparing their physiological effects. Crit Rev Food Sci Nutr 33, $103-148$.

Roberfroid M (1997) In Dietary Fiber in Health and Disease, pp. 211-219 [D Kritchevsky and C Bonfield, editors]. New York: Plenum Press.

Roberfroid M (2002) Functional foods: concepts and application to inulin and oligofructose. Br J Nutr 87, Suppl., S139-S143.

Roberfroid M, Van Loo J \& Gibson G (1998) The bifidogenic nature of chicory inulin and its hydrolysis products. $J$ Nutr 128, 11-19.

Roberfroid MB, Cumps J \& Devogelaer JP (2002) Dietary chicory inulin increases whole-body mineral density in growing male rats. J Nutr 132, 3599-3602.

Scholz-Ahrens K \& Schrezenmeier J (2002) Inulin, oligofructose and mineral metabolism - experimental data and mechanism. Br J Nutr 87, Suppl., S179-S186.

Scholz-Ahrens K, Schaafsma G, Van den Heuvel EGHM \& Schrezenmeier J (2001) Effects of prebiotics on mineral metabolism. Am J Clin Nutr 73, Suppl., 459S-464S.

Scholz-Ahrens K, Açil Y \& Schrezenmeier J (2002) Effect of oligofructose or dietary $\mathrm{Ca}$ on repeated $\mathrm{Ca}$ and phosphorus balances, 
bone mineralisation and trabecular structure in ovariectomized rats. $\mathrm{Br}$ J Nutr 88, 365-377.

Schulz AGM, Von Amelsvoort JMM \& Beynen AC (1993) Dietary native resistant starch but not retrograded resistant starch raises magnesium and Ca absorption in rats. J Nutr 123, 1724-1731.

Setchell KDR (1998) Phytoestrogens: the biochemistry, physiology, and implications for human health of soy isoflavones. Am J Clin Nutr 68 , Suppl., 1333S-1346S.

Setchell KDR \& Lydeking-Olsen E (2003) Dietary phytoestrogens and their effect on bone: evidence from in vitro and in vivo, human observational, and dietary intervention studies. Am J Clin Nutr 78, Suppl., 593S-609S.

Setchell KDR, Brown NM \& Lydeking-Olsen E (2002) The clinical importance of the metabolite equol. A clue to the effectiveness of soy and its isoflavones. J Nutr 132, 3577-3584.

Slemenda CW, Reister TK, Peacock M \& Johnston CC (1993) Bone growth in children following the cessation of $\mathrm{Ca}$ supplementation. J Bone Miner Res 8, S154.

Smith EL, Gilligan C, Smith PE \& Sempos CT (1989) Calcium supplementation and bone loss in middle-aged women. Am J Clin Nutr 50, 833-842.

Taguchi A, Otha A, Abe M, Baba S, Ohtsuki M, Takizawa T, Yuda Y \& Adachi T (1994) The influence of fructooligosaccharides on the bone of model rats with ovariectomized osteoporosis. Sci Rep Meija Seika Kaisha 33, 34-43.

Tahiri M, Tressol JC, Arnaud J, et al. (2003) Effect of short-chain fructooligosaccharides on intestinal $\mathrm{Ca}$ absorption and $\mathrm{Ca}$ status in postmenopausal women a stable-isotope study. Am J Clin Nutr 77, 449-457.

Takahara S, Morohashi T, Sano T, Ohta A, Yamada S \& Sasa R (2000) Fructooligosaccharide consumption enhances femoral bone volume and mineral concentration in rats. J Nutr 130, 1792-1795.

Teuri U, Kärkkäinen M, Lamberg-Allardt C \& Korpela R (1999) Addition of inulin to breakfast does not acutely affect serum ionized $\mathrm{Ca}$ and parathyroid hormone concentrations. Ann Nutr Metab 43, 356-364.

Trinidad TP, Wolever TMS \& Thompson LU (1996) Effect of acetate and propionate on $\mathrm{Ca}$ absorption from the rectum and distal colon of humans. Am J Clin Nutr 63, 574-578.

Uehara M, Ohta A, Sakai K, Suzuki K, Watanabe S \& Adlercreutz H (2001) Dietary fructooligosaccharides modify intestinal bioavailability of a single dose of genistein and daidzein and affect their urinary excretion and kinetics in blood of rats. J Nutr 131, 787-795.

US Department of Agriculture (1999) Supplementary data tables, USDA's 1994-1996. Continuing Survey Research Group BHNRC, Agricultural Research Service.
US Department of Health and Human Services (2000) Healthy People 2010. Understanding and Improving Health and Objectives for Improving Health, 2nd ed. Washington, DC: US Government Printing Office.

Van den Heuvel EGHM, Schaafsma G, Muys T \& Van Dokkum W (1998) Nondigestible oligosaccharides do not interfere with $\mathrm{Ca}$ and nonheme-iron absorption in young, healthy men. Am J Clin Nutr 67, $445-451$.

Van den Heuvel EGHM, Muys T, Van Dokkum W \& Schaafsma G (1999a) Oligofructose stimulates Ca absorption in adolescents. Am J Clin Nutr 69, 544-548.

Van den Heuvel EGHM, Muys T, Van Dokkum W \& Schaafsma G (1999b) Lactulose stimulates $\mathrm{Ca}$ absorption in postmenopausal women. J Bone Miner Res 7, 1211-1216.

Van den Heuvel EGHM, Schoterman MH \& Muijs T (2000) Transgalactooligosaccharides stimulate $\mathrm{Ca}$ absorption in postmenopausal women. J Nutr 130, 2938-2942.

Van Dokkum W (1995) The intake of selected minerals and trace elements in European countries. Nutr Res Rev 8, 271-302.

Van Loo J, Coussement P, De Leenheer L, Hoebregs H \& Smits G (1995) Inulin and oligofructose in the western diets. CRC Crit Rev Food Sci Nutr 35, 525-552.

Weaver CM (2000) The growing years and prevention of osteoporosis in later life. Proc Nutr Soc 59, 303-306.

Weaver CM \& Liebman M (2002) Biomarkers of bone health appropriate for evaluating functional foods designed to reduce risk of osteoporosis. Br J Nutr 88, Suppl., S225-S232.

Welten DC, Kemper HC, Post GB \& Van Staveren WA (1995) A metaanalysis of the effect of $\mathrm{Ca}$ intake on bone mass in young and middle aged females and males. J Nutr 125, 2802-2813.

Xu X, Wang HJ, Murphy PA, Cook L \& Hendrich S (1994) Daidzein is a more bioavailable soymilk isoflavone than is genistein in adult women. J Nutr 124, 825-832.

Younes H, Demigné C and Rémésy C (1996) Acidic fermentation in the caecum and magnesium in the large intestine of the rat. $\mathrm{Br} J \mathrm{Nutr}$ 75, 301-314.

Younes H, Coudray C, Bellanger J, Demigné C, Rayssiguier Y \& Rémésy C (2001) Effects of two fermentable carbohydrates (inulin and resistant starch) and their combination on $\mathrm{Ca}$ and magnesium balance in rats. $\mathrm{Br}$ J Nutr 86, 479-485.

Zafar T, Weaver C, Zhao D, Martin B \& Wastney M (2003) Inulin and calcium metabolism in ovariectomized (OVX) rats. Proc Exp Biol Meeting, San Diego, CA. 